A Publication of the Materials Research Society

Volume XII, Number 6 August 16/September 30, 1987 ISSN: 0883-7694

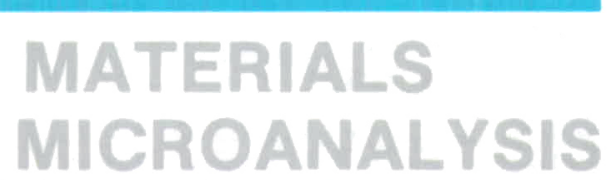

Techniques for

Materials

Microanalysis

C.R. Helms,

Guest Editor

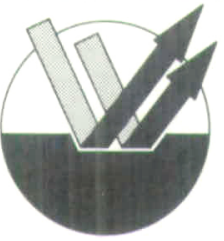

Materials Analysis with High

Energy Ion Beams Part I:

Rutherford Backscattering

H-J. Gossmann and

L.C. Feldman

Materials Analysis with High

Energy Ion Beams Part II:

Channeling and Other

Techniques

H-J. Gossmann and

L.C. Feldman

Materials Analysis with High

Energy Ion Beams Part III:

Elastic Recoil Detection

C.P.M. Dunselman.

W.M. Arnold Bik,

F.H.P.M. Habraken, and

W.F. van der Weg

Fundamentals of Secondary

Ion Mass Spectrometry

W. Katz and J.G. Newman

Fundamentals of Sputtered

Neutral Mass Spectrometry

U. Kaiser and J.C. Huneke

Surface Analysis by

Laser Ionization

J.B. Pallix, C.H. Becker, and

N. Newman

Fundamentals of X-Ray

Photoemission

Spectroscopy

F.J. Grunthaner

Advances in

Small Spot ESCA

C.E. Bryson III and

R.E. Chaney

Advances in Analytical Auger Electron Spectroscopy

C.C. Chang

New Directions in Auger

Microanalysis

R. Browning

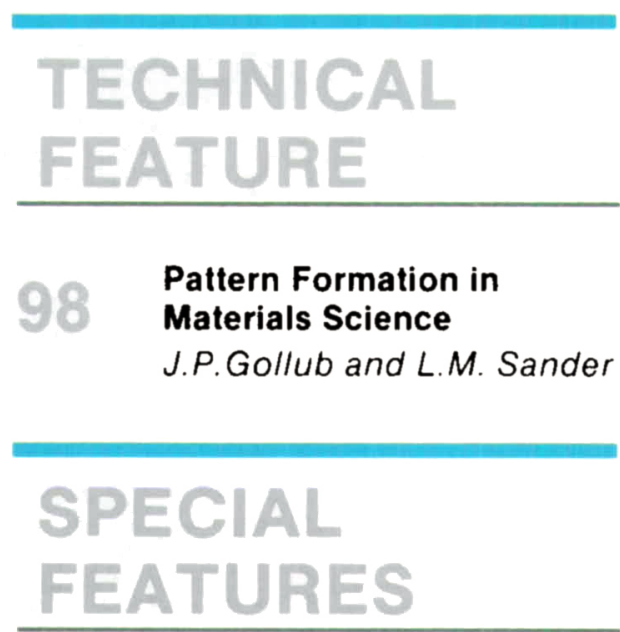

Up Close: The Ion Beam Materials Laboratory at Los Alamos National Laboratory

J.R. Tesmer, D.M. Parkin. and C.J. Maggiore

Up Close: Center for Materials Science at Los Alamos National

Laboratory

D.M. Parkin

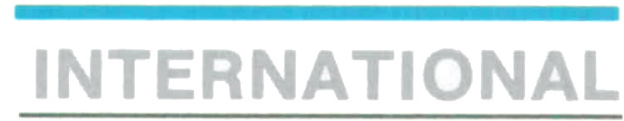

1987 E-MRS Meeting is Largest in History

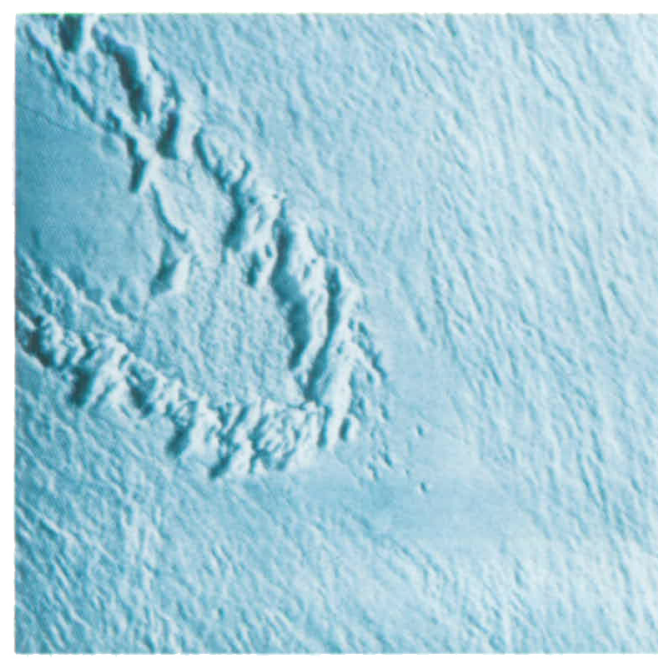

ON THE COVER: False-color multiple Auger image of a reaction zone between a SiC fiber and a Ti alloy matrix shown in the SEM micrograph at the left. The false-color image was created from a multispectral scanning electron microscope Auger image by simultaneously collecting the three regions of the secondary electron spectrum corresponding to Auger transitions due to $T i$. $S i$, and $C$. These three intensities were displayed as a scatter diagram. and the regions corresponding to elemental correlations were colored. The color image therefore shows not Auger intensities, but elemental associations: yellow-gold corresponds to the Ti matrix, blue to $\mathrm{Ti}_{4} \mathrm{Si}_{3}$. red to TiC. purple to SiC. and rust plus green to carbon contamination. These techniques are discussed in "New Directions in Auger Microanalysis" by R. Browning in this issue. Photo courtesy of R. Browning. 


\section{MIRS BULLETIN}

Materials Research Society - 9800 McKnight Road, Suite 327 • Pittsburgh, PA 15237

\section{MRS BULLETIN EDITORIAL BOARD}

\section{MRS BULLETIN}

\section{Editorial Board Chairman}

E. N. Kaufmann

Lawrence Livermore

Associate Editor-Europe

A. Golanski

Centre National d'Études des

Télécommunications

CNS-RPT

Chemin du Vieux Chêne BP 98

38243 Meylan Cedex France

(33) 76514067
National Laboratory
Editor

G. A. Oare

(412) $367-3036$

Assistant Editor

F. M. Wieloch

(412) $367-3036$

Design/Production

C. Love

R. C. Whitehouse

(412) 367-3003

Editorial Assistant

$J$. Dininny

(412) 367-3036
Guest Editor:

C. R. Helms

Advertising and Circulation

M. E. Kaufold

(412) 367-3036
MINKO BALKANSKI

University of Pierre and Marie Curie Laboratoire de Physique des Solides

4 Place Jussieu. Tour 13

75230 Paris Cedex 05, France

telephone: $336-25-25$

RICHARD B. FAIR

Vice President

Research Program Management

Microelectronics Center of North Carolina P.O. Box 12889

Research Triangle Park NC 27709

telephone: (919) 248-1800

FRANK Y. FRADIN Director

Materials Science Division Argonne National Laboratory

9700 South Cass Avenue Argonne, IL 60439

telephone: (312) 972-4925

SHU-EN HSU Director

Materials R\&D Center

Chung Shan Institute of

Science and Technology P.O. Box 1-26

Lung-Tan, Taiwan, China Cable: CHUNSHANINST SHIMEN TAIWAN

RALPH J. JACCODINE

Sherman Fairchild Professor of Solid State Studies

Sherman Fairchild Laboratory 161 Lehigh University Bethlehem, PA 18015 telephone: (215) 862-3950

HIROSHI KAMIMURA

Second Vice President

R. P. H. Chang

Northwestern University

Executive Director

Materials Research Society

John B. Ballance

\section{EUROPEAN MRS}

\section{P. Siffert}

Centre de Recherches Nucléaire

Laboratoire PHASE

67037 Strasbourg Cedex, France

(88) 286543 Department of Physics

Faculty of Science University of Tokyo

7-3-1 Hongo, Bunkyo-ke Tokyo 113 Japan

telephone: 03-812-2111

telex: UTPHYSIC $\mathrm{J} 23472$

S. M. Kelso

Center

G. E. Pike

Sandia National Laboratories

ELTON N. KAUFMANN (Chairman)

Lawrence Livermore National Laboratory

P. O. Box 808 L-350

Livermore, CA 94550

telephone: (415) 423-2640

R. KRISHNAN

Naval Chemical \& Metallurgical Laboratory

Naval Dockyard

Bombay 400 023. India

telex: 011-3192 NCML IN

JAMES L. MERZ

Associate Dean

for Research Development

College of Engineering

University of California

Santa Barbara, CA 93106

telephone: (805) 961-4446
SUSUMU NAMBA

Professor of Electrical Engineering

Faculty of Engineering Science

Osaka University. Toyonaka

Osaka. Japan 560

JULIA M. PHILLIPS

AT\&T Bell Laboratories

Room 1E-431

600 Mountain Avenue

Murray Hill, NJ 07974

telephone: (201) 582-4428

EMANUELE RIMIN

University of Catania

Department of Physics 57 Corso Italia

I 95129 Catania, Italy

telephone: $37-70-61$

telex: 911554 INFNCT I

RUSTUM ROY

Materials Research Laboratory

Pennsylvania State University

University Park, PA 16802

telephone: (814) 865-3424

RICHARD L, SCHWOEBEL Directorate 1800

Sandia National Laboratories P.O. Box 5800

Albuquerque, NM 87185

telephone: (505) 844-9273

G. D. W SMITH

University of Oxford

Department of Metallurgy

and Science of Materials Parks Road

Oxford OX1 $3 \mathrm{PH}$. England

TAKUO SUGANO

Professor of Engineering

Department of Electronic Engineering

University of Tokyo

7-3-1 Hongo, Bunkyo-ku Tokyo 113 Japan

telephone: 03-812-2111, ext. 6675

C. W. WHITE

Solid State Division

Oak Ridge National Laboratory

Oak Ridge, TN 37831

telephone: (615) 574-6295

J. S. WILLIAMS

Royal Melbourne Institute of Technology

Microelectronics Tech. Center

124 Latrobe Street

Melbourne Victoria 3000 . Australia

telephone: 03-660-2459 XIE XIDE

Professor of Physics and President

Fudan University

Shanghai. China

\section{ABOUT THE MATERIALS RESEARCH SOCIETY}

The Materiais Research Society (MRS) is a nonprofit scientific association founded in 1973 to promote interdisciplinary goal-oriented basic research on materials of technological importance. Membership in the Society inciudes more than 5,900 scientists from industrial, government, and university research laboratories in the United States and more than 25 countries.

The Society's interdisciplinary approach to the exchange of technical information is qualitatively different from that provided by singledisciplinary professional societies because it promotes technical ex change across the various fields of science affecting materials development. MAS sponsors two major international annual meetings encompassing approximately 30 topical symposia, as well as numerous single-topic scientific meetings each year. It recognizes professional and technical excellence, conducts short courses, and fosters technical exchange in various local geographical regions through Section activities and Student Chapters on university campuses.

MRS is an Affiliated Society of the American Institute of Physics and participates in the international arena of materials research through associations with professional organizations such as European MRS.

MRS publishes symposia proceedings, the MRS BULLETIN. Journal of Materials Research, and other volumes on current scientific developments.

For further information on the Society's activities, contact MRS Headquarters, 9800 McKnight Road, Suite 327. Pittsburgh, Pennsylvania 15237: telephone (412) 367-3003. 


\section{Cut your costs in surface analysis...}

Choosing an XPS system used to be a double-edged sword: You could opt for high performance at a correspondingly high price or settle for limited capabilities at a low price. Today, there's an alternative: the VG ESCALAB 200-X. It's the multifunctional XPS system that gives you the edge in small area surface analysis while dramatically cutting your costs in both initial investment and operation.

Compare these ESCALAB 200-X features with those of premiumpriced systems: sensitivity. up to 4Mcps on Ag3d5/2; spatial resolution down to $150 \mu \mathrm{m}$ analyzed diameter; energy resolution less than $0.45 \mathrm{eV}$ with monochromator; high throughput with multispecimen handling; flexibility with monochromator, AES-SAM-ISS options; UHV down to $10^{-10}$ mbar with sublimator.

Call VG today for more details on the cost-cutting selected area XPS system for cutting-edge analysis - ESCALAB 200-X, the affordable alternative.

\section{... and still keep your results at the cutting edge.}

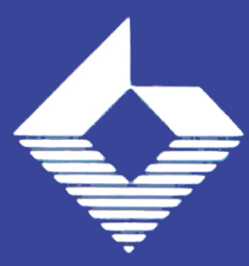

\section{VE INSTRUMENTS Surface Analysis Systems}

A VE INSTRUMENTS GROUP COMPANY
USA. VG Instruments Inc. 32 Commerce Center, Cherry Hil Dnve. Danvers, MA 01923. Tel. (617) $77-8034$ VG Scientific Limited, Imberhorne Lane. East Grinstead. West Sussex. RH19 1 UB. England. Tol 034227211 CANADA. VG Instruments (Canada) Inc. 5929 Transcanadienne. St. Laurent, Quebec. H4T 1A1. Tel. (514) 744-5519 WEST GERMANY. VG Instruments GmbH. Gustav-Nachtigal-Strasse 4. 6200. Wiesbaden. Tel. (6121) 71090. FRANCE. VG Instruments. 3 Rue du Marechal de Lattre de Tassigny, 78150 Le Chesnay. Tel. (1) 39555120. ITALY. VG Instruments Lmited, Viale Dell Assunta 101, 20063 Cernusco Sul Naviglio. Milano. Tol (2) 9248800 THE NETHERLANDS. VG Instruments bv, PO Box 171, 1380 AD, Weesp fol. (2940) 80484 CHINA. VG Instruments, Room 7059. Xi Vuan Hotel, Erigou, Xurao. Beuing. Fel. 690721 Ext 759 JAPAY KONG. VG Instuments Asia Limiled, GPO Bax 217, Hong Kong. Tel. (5) 86136 